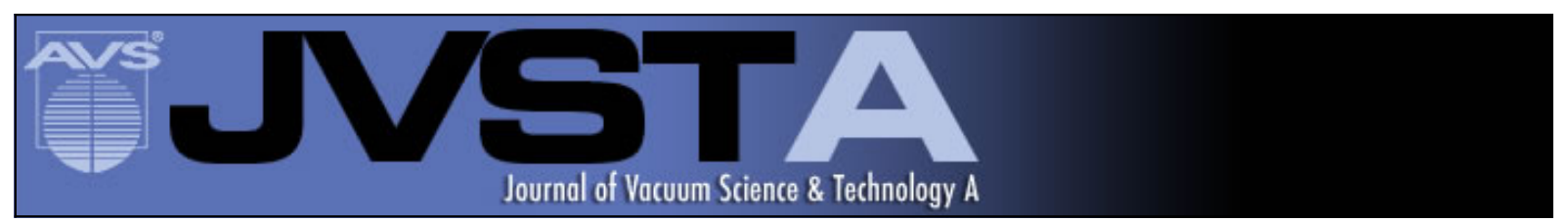

\title{
Sintered $\mathrm{Cr} / \mathrm{Pt}$ and Ni/Au ohmic contacts to B12P2
}

Clint D. Frye, Sergei O. Kucheyev, James H. Edgar, Lars F. Voss, Adam M. Conway, Qinghui Shao, and

Rebecca J. Nikolić

Citation: Journal of Vacuum Science \& Technology A 33, 031101 (2015); doi: 10.1116/1.4917010

View online: http://dx.doi.org/10.1116/1.4917010

View Table of Contents: http://scitation.aip.org/content/avs/journal/jvsta/33/3?ver=pdfcov

Published by the AVS: Science \& Technology of Materials, Interfaces, and Processing

\section{Articles you may be interested in}

$\mathrm{Cr} / \mathrm{Pt}$ Ohmic contacts to B 12 As 2

Appl. Phys. Lett. 87, 042103 (2005); 10.1063/1.2001760

Effect of an indium-tin-oxide overlayer on transparent Ni/Au ohmic contact on p-type GaN Appl. Phys. Lett. 82, 61 (2003); 10.1063/1.1534630

Chemical, electrical, and structural properties of Ni/Au contacts on chemical vapor cleaned p-type GaN

J. Appl. Phys. 91, 9151 (2002); 10.1063/1.1471578

Oxidized Ni/Pt and Ni/Au ohmic contacts to p-type GaN

Appl. Phys. Lett. 76, 3703 (2000); 10.1063/1.126755

Low-resistance Pt/Ni/Au ohmic contacts to p-type GaN

Appl. Phys. Lett. 74, 70 (1999); 10.1063/1.123954

\section{FIDEN}

\section{Instruments for Advanced Science}

w www.HidenAnalytical.com E info@hiden.co.uk

CLICK TO VIEW our product catalogue

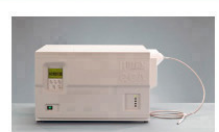

Gas Analysis

dynamic measurement of reaction gas streams cataysis and thermal analysis

molecular beam studies

, dissolved species probes

fermentation, environmental and ecological studies

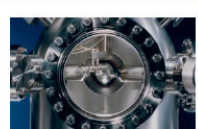

Surface Science

, UHVTPD

SIMS end point detection in ion beam etch

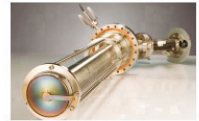

Plasma Diagnostics plasma source characterization etch and deposition process reaction

, analysis of neutral and radical species

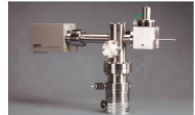

Vacuum Analysis partial pressure measurement and control of process gases reactive sputter process control vacuum diagnostics , 


\title{
Sintered $\mathrm{Cr} / \mathrm{Pt}$ and $\mathrm{Ni} / \mathrm{Au}$ ohmic contacts to $\mathrm{B}_{12} \mathrm{P}_{2}$
}

\author{
Clint D. Frye $\mathrm{e}^{\mathrm{a})}$ \\ Lawrence Livermore National Laboratory, Livermore, California 94550 and Department of Chemical \\ Engineering, Kansas State University, Manhattan, Kansas 66506
}

Sergei O. Kucheyev

Lawrence Livermore National Laboratory, Livermore, California 94550

James H. Edgar

Department of Chemical Engineering, Kansas State University, Manhattan, Kansas 66506

Lars F. Voss, Adam M. Conway, Qinghui Shao, and Rebecca J. Nikolićb)

Lawrence Livermore National Laboratory, Livermore, California 94550

(Received 29 January 2015; accepted 24 March 2015; published 9 April 2015)

\begin{abstract}
Icosahedral boron phosphide $\left(\mathrm{B}_{12} \mathrm{P}_{2}\right)$ is a wide-bandgap semiconductor possessing interesting properties such as high hardness, chemical inertness, and the reported ability to self-heal from irradiation by high energy electrons. Here, the authors developed $\mathrm{Cr} / \mathrm{Pt}$ and $\mathrm{Ni} / \mathrm{Au}$ ohmic contacts to epitaxially grown $\mathrm{B}_{12} \mathrm{P}_{2}$ for materials characterization and electronic device development. $\mathrm{Cr} / \mathrm{Pt}$ contacts became ohmic after annealing at $700^{\circ} \mathrm{C}$ for $30 \mathrm{~s}$ with a specific contact resistance of $2 \times 10^{-4} \Omega \mathrm{cm}^{2}$, as measured by the linear transfer length method. Ni/Au contacts were ohmic prior to any annealing, and their minimum specific contact resistance was $\sim 1-4 \times 10^{-4} \Omega \mathrm{cm}^{2}$ after annealing over the temperature range of $500-800^{\circ} \mathrm{C}$. Rutherford backscattering spectrometry revealed a strong reaction and intermixing between $\mathrm{Cr} / \mathrm{Pt}$ and $\mathrm{B}_{12} \mathrm{P}_{2}$ at $700^{\circ} \mathrm{C}$ and a reaction layer between $\mathrm{Ni}$ and $\mathrm{B}_{12} \mathrm{P}_{2}$ thinner than $\sim 25 \mathrm{~nm}$ at $500{ }^{\circ} \mathrm{C}$. ( 2015 American Vacuum Society.
\end{abstract}

[http://dx.doi.org/10.1116/1.4917010]

\section{INTRODUCTION}

Boron and phosphorus form two distinct semiconductor compounds, cubic zincblende boron phosphide (BP) and rhombohedral $\mathrm{B}_{12} \mathrm{P}_{2}$, which in addition to having different stoichiometries also have different crystal structures and electronic properties. $\mathrm{B}_{12} \mathrm{P}_{2}$, often called icosahedral boron phosphide, is a wide-bandgap semiconductor $\left[E_{g}=3.35 \mathrm{eV}\right.$ (Ref. 1)] composed of boron icosahedra with interlinking phosphorus-phosphorus chains. It possesses many properties such as high hardness and chemical inertness that make it desirable as a semiconductor that can withstand extreme environments. Moreover, $\mathrm{B}_{12} \mathrm{P}_{2}$ can reportedly self-heal from intense beta-irradiation. ${ }^{2,3}$ This unusual property makes $\mathrm{B}_{12} \mathrm{P}_{2}$ very attractive for a number of technologies, including radiation detection, electronics in harsh radiation environments, and radioisotope batteries-devices that directly convert nuclear energy into electricity.

Recent advancements in the improved heteroepitaxial growth of a similar rhombohedral boride, $\mathrm{B}_{12} \mathrm{As}_{2}$, have been achieved on $\mathrm{SiC}$, including suppression of double-position twinning ${ }^{4,5}$ and control of $p$-type doping ${ }^{6}$ (note: $n$-type conductivity in neither $\mathrm{B}_{12} \mathrm{P}_{2}$ nor $\mathrm{B}_{12} \mathrm{As}_{2}$ has been reported yet). Heterojunction $p n$-diodes of $p-\mathrm{B}_{12} \mathrm{As}_{2} / n$-SiC have also been demonstrated. ${ }^{7}$ However, before $\mathrm{B}_{12} \mathrm{P}_{2}$ diodes can be fabricated and characterized, a process for creating low resistance ohmic contacts to $p$-type $\mathrm{B}_{12} \mathrm{P}_{2}$ must be developed.

For many wide-bandgap materials, forming a low resistance ohmic contact is challenging. For instance, $p$-type GaN

\footnotetext{
${ }^{a)}$ Electronic mail: frye6@1lnl.gov

b)Electronic mail: nikolic1@1lnl.gov
}

contacts typically have specific contact resistances on the order of $10^{-4}-10^{-6} \Omega \mathrm{cm}^{2}{ }^{8}$ Ino et al. ${ }^{9}$ recently published a study on the electrical characteristics of various metal contacts to $n$-type $\left(n \sim 10^{19} \mathrm{~cm}^{-3}\right)$ cubic BP, reporting specific contact resistances of $10^{-2}-10^{-5} \Omega \mathrm{cm}^{2}$. Wang et al. ${ }^{10}$ developed $\mathrm{Cr} / \mathrm{Pt}$ ohmic contacts with a specific contact resistance of $3 \times 10^{-4} \Omega \mathrm{cm}^{2}$ to $\mathrm{B}_{12} \mathrm{As}_{2}$ by annealing at $700{ }^{\circ} \mathrm{C}$. However, there is little data in the literature on metal contacts to $\mathrm{B}_{12} \mathrm{P}_{2}$. Use of sintered $\mathrm{Al}$ has been mentioned in multiple publications by Kumashiro et al., ${ }^{11,12}$ and while $\mathrm{Si}$ has been used to form a heterojunction diode with $\mathrm{B}_{12} \mathrm{P}_{2},{ }^{13}$ the current-voltage characteristics display a nearly ohmic relationship.

While studies on ohmic contacts to $\mathrm{BP}$ and $\mathrm{B}_{12} \mathrm{As}_{2}$ have been reported, this is the first study on the characterization of ohmic contacts to $\mathrm{B}_{12} \mathrm{P}_{2}$, which will enable further material characterization and development of functional $\mathrm{B}_{12} \mathrm{P}_{2}$ electronic devices. Here, $\mathrm{Cr} / \mathrm{Pt}$ and $\mathrm{Ni} / \mathrm{Au}$ ohmic metal$\mathrm{B}_{12} \mathrm{P}_{2}$ contacts have been developed. Since $\mathrm{Cr} / \mathrm{Pt}$ forms ohmic contacts to $\mathrm{B}_{12} \mathrm{As}_{2},{ }^{10}$ the same metal scheme was tested to determine if the process could be extended to $\mathrm{B}_{12} \mathrm{P}_{2}$. Additionally, $\mathrm{Cr}$ forms conductive borides ${ }^{14}$ and phosphides ${ }^{15}$ of varying composition that are stable to high temperatures. ${ }^{16,17} \mathrm{Pt}$ also alloys with both $\mathrm{B}$ and $\mathrm{P}$, even forming eutectics below $600^{\circ} \mathrm{C}^{18,19} \mathrm{Ni} / \mathrm{Au}$, a wellestablished ohmic contact to $p$-type $\mathrm{GaN},{ }^{8}$ was chosen as an alternate metal scheme. Like $\mathrm{Cr}$, Ni forms various stoichiometries of electrically conductive Ni-B alloys ${ }^{20}$ and nickel phosphides. ${ }^{21}$ Further, Ni readily reacts with and/or dissolves both $\mathrm{BP}$ and $\mathrm{B}_{12} \mathrm{P}_{2},{ }^{22-25}$ aiding in the sintering process. However, the nickel phosphides and borides have melting points at temperatures above $800^{\circ} \mathrm{C}$, which may lead to 
stability at higher temperatures than $\mathrm{Cr} / \mathrm{Pt}$. In addition, $\mathrm{Ni}$ has a large work function, which may reduce the barrier height. A top Au layer was used to provide a conductive oxide barrier for probing.

\section{EXPERIMENTAL METHODS AND PROCESSING}

$\mathrm{B}_{12} \mathrm{P}_{2}$ was grown epitaxially on on-axis (0001) $6 \mathrm{H}-\mathrm{SiC}$ substrates via the thermal decomposition of $\mathrm{B}_{2} \mathrm{H}_{6}$ and $\mathrm{PH}_{3}$ in $\mathrm{H}_{2}$ at $1300^{\circ} \mathrm{C}$ and a pressure of $100 \mathrm{Torr}$. Si-face, c-plane $\mathrm{SiC}$ was chosen due to its relatively low lattice mismatch of $2.54 \%$ and high thermal stability compared to $\mathrm{Si}$. A detailed report on the epitaxial growth of $\mathrm{B}_{12} \mathrm{P}_{2}$ on $\mathrm{SiC}$ will be provided in a future publication. To prevent current flow through the substrate during electrical measurements, vanadiumdoped, semi-insulating $\mathrm{SiC}$ was used. The $\mathrm{B}_{12} \mathrm{P}_{2}$ films were nominally $2 \mu \mathrm{m}$ thick as measured by cross-sectional SEM. The hole concentration was $8 \times 10^{18} \mathrm{~cm}^{-3}$ as determined from Hall Effect measurements using the van der Pauw method and $\mathrm{Ni} / \mathrm{Au}$ ohmic contacts fabricated as described below.

Annealing epitaxial $\mathrm{B}_{12} \mathrm{As}_{2}$ above $600^{\circ} \mathrm{C}$ drastically reduces its sheet resistance. ${ }^{6,10}$ This effect has also been observed in $\mathrm{B}_{12} \mathrm{P}_{2}$ films grown in our group, which may influence the electrical properties of the metal-semiconductor interface independently of any sintering effects. To decouple the effects of annealing-induced changes in the sheet resistance from the sintering of metal contacts, the $\mathrm{B}_{12} \mathrm{P}_{2}$ films were annealed in $\mathrm{Ar}$ at $800^{\circ} \mathrm{C}$ for $30 \mathrm{~s}$ before any metal contacts were deposited.

$\mathrm{Cr} / \mathrm{Pt}(500 \AA / 1000 \AA)$ and $\mathrm{Ni} / \mathrm{Au}(1000 \AA / 1000 \AA)$ were evaluated as ohmic contacts to $\mathrm{B}_{12} \mathrm{P}_{2}$. The sheet resistance and specific contact resistance were measured by the linear transfer length method (TLM). The TLM patterns nominally consisted of $100 \times 100 \mu \mathrm{m}^{2}$ metal pads separated by spacings of 5, 10, 25, 40, 50, and $75 \mu \mathrm{m}$ (see the inset of Fig. 1).

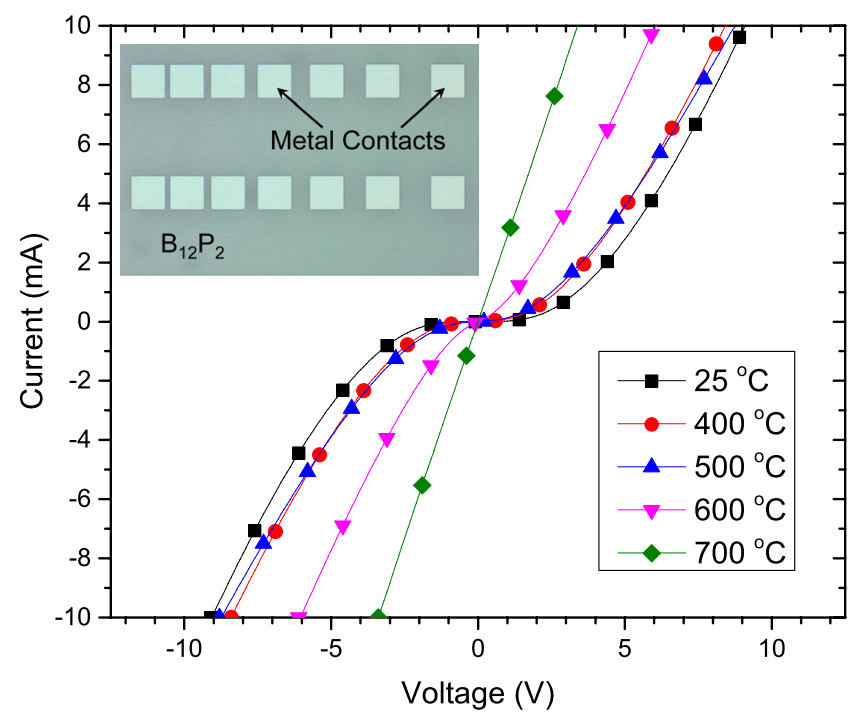

FIG. 1. (Color online) Progression of the current-voltage curve for $\mathrm{Cr} / \mathrm{Pt}$ contacts with a spacing of $10 \mu \mathrm{m}$ as they are annealed at subsequently higher temperatures, as indicated in the legend. Inset is an optical micrograph of two sets of TLM patterns. Each metal pad is nominally $100 \times 100 \mu \mathrm{m}^{2}$.
The metal contacts were formed via photolithography and electron-beam evaporation. The $\mathrm{B}_{12} \mathrm{P}_{2}$ films were cleaned in an $\mathrm{O}_{2}$ plasma, dipped in buffered oxide etch for $10 \mathrm{~s}$, quickly rinsed in deionized water, and blown dry with $\mathrm{N}_{2}$ immediately prior to loading into the electron-beam evaporator.

After the metal was patterned, the samples were annealed in $\mathrm{Ar}$ in a rapid thermal annealing furnace. The films were annealed for $30 \mathrm{~s}$ at sequentially higher temperatures in $100{ }^{\circ} \mathrm{C}$ increments. Current-voltage $(I-V)$ measurements were taken after each anneal on three adjacent sets of TLM patterns. The purpose of these measurements was to determine the minimum anneal temperature needed to form ohmic contacts for a given metal scheme and to test the effect of anneal temperature on the specific contact resistance. After ohmic conduction was achieved, the contact resistance was extracted from the current-voltage plots in the range of $-1 \mathrm{~V}$ to $+1 \mathrm{~V}$ with standard techniques. ${ }^{26}$

Because Rutherford backscattering spectrometry (RBS) is a nondestructive technique that provides depth-resolved information on individual elements independently of one another, it was employed to study the interface between the metals and $\mathrm{B}_{12} \mathrm{P}_{2}$ and to delineate the diffusion of metals into $\mathrm{B}_{12} \mathrm{P}_{2}$ and/or the diffusion of $\mathrm{B}$ or $\mathrm{P}$ into the metal. Since RBS may induce changes in the electrical properties of the film or contacts, separate samples were used for RBS analysis. Measurements were repeated on the same samples before and after annealing. They were done with a $2 \mathrm{MeV}$ ${ }^{4} \mathrm{He}^{+}$ion beam incident normal to the sample surface and a detector located at $164^{\circ}$ from the incident beam direction.

\section{RESULTS AND DISCUSSION}

The conduction mechanism between a metal and a semiconductor can be predicted by comparing the thermal energy, $k T$, with the characteristic energy, $E_{00}$, which is a strong function of the carrier concentration. ${ }^{27}$ For $\mathrm{B}_{12} \mathrm{P}_{2}$ with a hole concentration of $8 \times 10^{18} \mathrm{~cm}^{-3}, E_{00} \approx k T$. In this case, the conduction mechanism is in the thermionic field emission regime prior to sintering.

Despite the high background doping level in the $\mathrm{B}_{12} \mathrm{P}_{2}$ films, the carrier concentration is not large enough to facilitate pure field emission. Thus, the barrier height must be lowered by choosing a high work function metal or the contacts must react with and/or effectively dope the surface of the $\mathrm{B}_{12} \mathrm{P}_{2}$ film to induce ohmic conduction. With this information in mind, $\mathrm{Cr} / \mathrm{Pt}$ and $\mathrm{Ni} / \mathrm{Au}$ are evaluated. The results are summarized in Table I.

TABLE I. Work function, optimum anneal temperature (for $30 \mathrm{~s}$ anneals), and the corresponding specific contact resistance for the metals studied here.

\begin{tabular}{lcc}
\hline \hline & $\mathrm{Cr} / \mathrm{Pt} 500 \AA / 1000 \AA$ & $\mathrm{Ni} / \mathrm{Au} 1000 \AA / 1000 \AA$ \\
\hline Work function (Ref. 28) & $4.5 / 5.65 \mathrm{eV}$ & $5.15 / 5.1 \mathrm{eV}$ \\
Anneal temperature & $700^{\circ} \mathrm{C}$ & $500^{\circ} \mathrm{C}$ \\
Specific contact resistance & $2 \times 10^{-4} \Omega \mathrm{cm}^{2}$ & $3 \times 10^{-4} \Omega \mathrm{cm}^{2}$ \\
\hline \hline
\end{tabular}




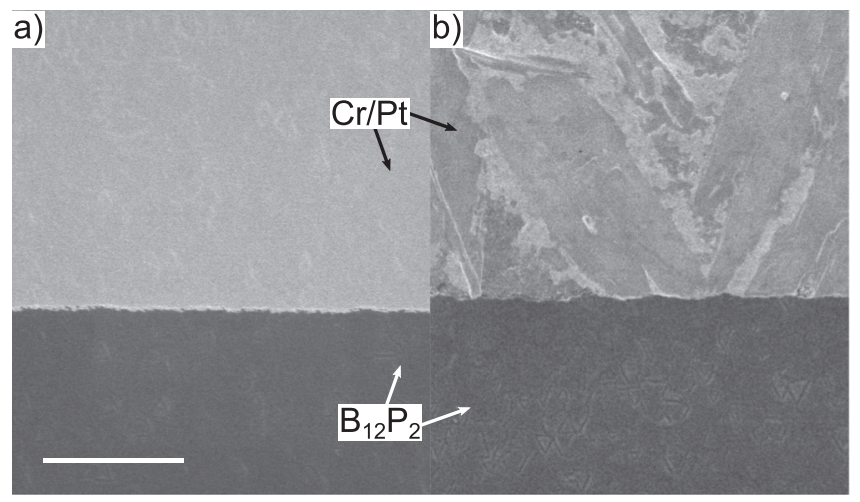

FIG. 2. SEM micrograph of $\mathrm{Cr} / \mathrm{Pt}$ contact edges (a) before annealing and (b) after annealing at $700^{\circ} \mathrm{C}$ for $30 \mathrm{~s}$. The contact is smooth and uniform prior to annealing, and the morphology of the contact becomes much rougher after the anneal. The scale bar is $6 \mu \mathrm{m}$.

\section{A. $\mathrm{Cr} / \mathrm{Pt}$ contacts}

$\mathrm{Cr} / \mathrm{Pt}$ contacts were annealed at $400,500,600$, and $700^{\circ} \mathrm{C}$ for $30 \mathrm{~s}$ at each temperature. After annealing at $700^{\circ} \mathrm{C}$, conduction became ohmic. The progression of the $I-V$ characteristics can be seen in Fig. 1. The $I-V$ curve changes only slightly after the 400 and $500^{\circ} \mathrm{C}$ anneals but becomes progressively linear after the 600 and $700{ }^{\circ} \mathrm{C}$ anneals. At $700^{\circ} \mathrm{C}$, the $\mathrm{Cr} / \mathrm{Pt}$ contacts visibly react with the $\mathrm{B}_{12} \mathrm{P}_{2}$ film, apparently even wetting it [Fig. 2(b)]. Cr does not form a eutectic with $\mathrm{B}, \mathrm{P}$, or Pt below $1300^{\circ} \mathrm{C}$ (Refs. 16, 17, and 29) and by itself is unlikely to cause wetting of the contact to the semiconductor. However, Pt readily forms phosphides that have melting points below $700^{\circ} \mathrm{C}$ and as low as $590^{\circ} \mathrm{C}{ }^{19}$ The temperature of these phase changes corresponds well to the changes in electrical properties and surface morphology observed here.

Figure 3 shows the RBS spectra collected before any heat treatment of the contacts and after annealing at $700^{\circ} \mathrm{C}$ for $30 \mathrm{~s}$. Prior to annealing, $\mathrm{Cr}$ and $\mathrm{Pt}$ form discrete peaks,

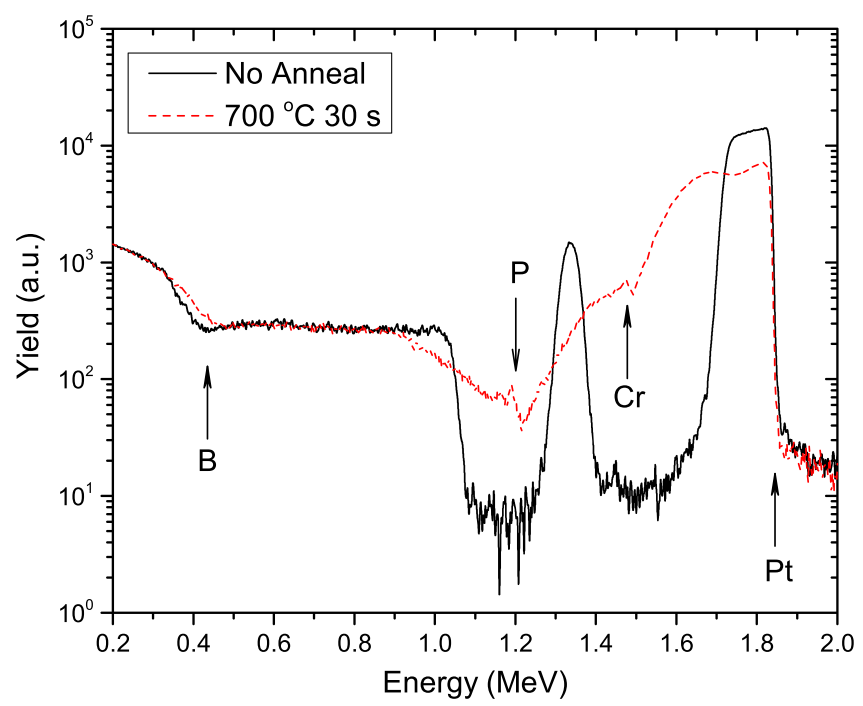

FIG. 3. (Color online) Semi-log plot of RBS spectra for $\mathrm{Cr} / \mathrm{Pt}$ contacts before any heat treatment and after annealing at $700^{\circ} \mathrm{C}$ for $30 \mathrm{~s}$. The positions of the surface peaks of $\mathrm{Pt}, \mathrm{Cr}, \mathrm{P}$, and $\mathrm{B}$ are denoted by arrows. corresponding to nonintermixed $\mathrm{Cr}$ and $\mathrm{Pt}$ layers. Also, sharp $\mathrm{B}$ and $\mathrm{P}$ edges can be identified. The signals of the $\mathrm{Cr}, \mathrm{P}$, and $\mathrm{B}$ edges (roughly located at $1.36,1.05$, and $0.35 \mathrm{MeV}$, respectively) are shifted to energies lower than the surface peak energies denoted by arrows in Fig. 3 because they are not located at the sample surface but are buried beneath other layers. After annealing, Cr, Pt, P, and B peaks are dramatically broadened. The large Pt shift to lower energies (i.e., to larger depths from the sample surface) represents its diffusion through the $\mathrm{Cr}$ layer to the underlying $\mathrm{B}_{12} \mathrm{P}_{2}$. The broadening of the $\mathrm{Cr}$ peak is consistent with such interdiffusion. Both $\mathrm{B}$ and $\mathrm{P}$ edges are shifted to higher energies, indicating that not only does $\mathrm{B}_{12} \mathrm{P}_{2}$ react with $\mathrm{Cr} / \mathrm{Pt}$, but both $\mathrm{B}$ and $\mathrm{P}$ atoms are mobile at $700{ }^{\circ} \mathrm{C}$ and rapidly diffuse toward the surface. $\mathrm{P}$ diffuses completely to the sample surface, as evidenced by a peak at $1.20 \mathrm{MeV}$, corresponding to scattering from $\mathrm{P}$ atoms at the sample surface. In addition to the morphology change, the large amount of mixing and fast diffusion of the species involved at this temperature is consistent with the formation of a liquid eutectic.

After annealing at $700{ }^{\circ} \mathrm{C}$ for $30 \mathrm{~s}$, the specific contact resistance was $2 \times 10^{-4} \Omega \mathrm{cm}^{2}$. In an attempt to further lower the contact resistance, the contacts were annealed repeatedly at $700^{\circ} \mathrm{C}$ in $30 \mathrm{~s}$ increments. Higher annealing temperatures were avoided to prevent dewetting and lateral spreading of the contact. After annealing for two cumulative minutes at $700^{\circ} \mathrm{C}$, the contact resistance did not decrease but rather slightly increased to $3 \times 10^{-4} \Omega \mathrm{cm}^{2}$ with no further change in surface morphology.

The minimum specific contact resistance for $\mathrm{Cr} / \mathrm{Pt}$ to $\mathrm{B}_{12} \mathrm{P}_{2}$ in this study is similar to the minimum values of $\sim 2-3 \times 10^{-4} \Omega \mathrm{cm}^{2}$ reported by Wang et al. ${ }^{10}$ for $\mathrm{Cr} / \mathrm{Pt}$ contacts to $\mathrm{B}_{12} \mathrm{As}_{2}$. In both studies, the lowest contact resistance is attained after annealing at $700^{\circ} \mathrm{C}$ for $30 \mathrm{~s} . \mathrm{B}_{12} \mathrm{P}_{2}$ and $\mathrm{B}_{12} \mathrm{As}_{2}$ could be expected to behave similarly due to their similar structure and comparable band gaps of 3.35 (Ref. 1) and $3.37 \mathrm{eV},{ }^{30}$ respectively. Also, since both materials are largely composed of $\mathrm{B}$, the contact resistances may also be dominated by B-Cr and B-Pt interactions, thus masking differences between each material. In contrast, however, $\mathrm{Cr} / \mathrm{Pt}$ contacts to $\mathrm{B}_{12} \mathrm{As}_{2}$ are suggested to be ohmic before annealing, ${ }^{10}$ while $\mathrm{Cr} / \mathrm{Pt}$ contacts to $\mathrm{B}_{12} \mathrm{P}_{2}$ only become ohmic after annealing at $700^{\circ} \mathrm{C}$.

\section{B. $\mathrm{Ni} / \mathrm{Au}$ contacts}

The $\mathrm{Ni} / \mathrm{Au}$ contacts were annealed sequentially at 200 , $300,400,500,600,700$, and $800^{\circ} \mathrm{C}$ for $30 \mathrm{~s}$ at each temperature. As can be seen in Fig. 4, the contacts are ohmic before any annealing. The annealing progression of the $I-V$ curve can be broken into two regimes. In the first regime, annealing up to $400^{\circ} \mathrm{C}$ causes essentially no change in the $I-V$ curve. A step change in the $I-V$ characteristics occurs after annealing at $500{ }^{\circ} \mathrm{C}$ for $30 \mathrm{~s}$, marking a second regime where the specific contact resistance decreases by an order of magnitude. Subsequently, higher temperature anneals, however, do not drastically affect the $I-V$ curve. This effect is better illustrated in Fig. 5, showing the specific contact resistance 


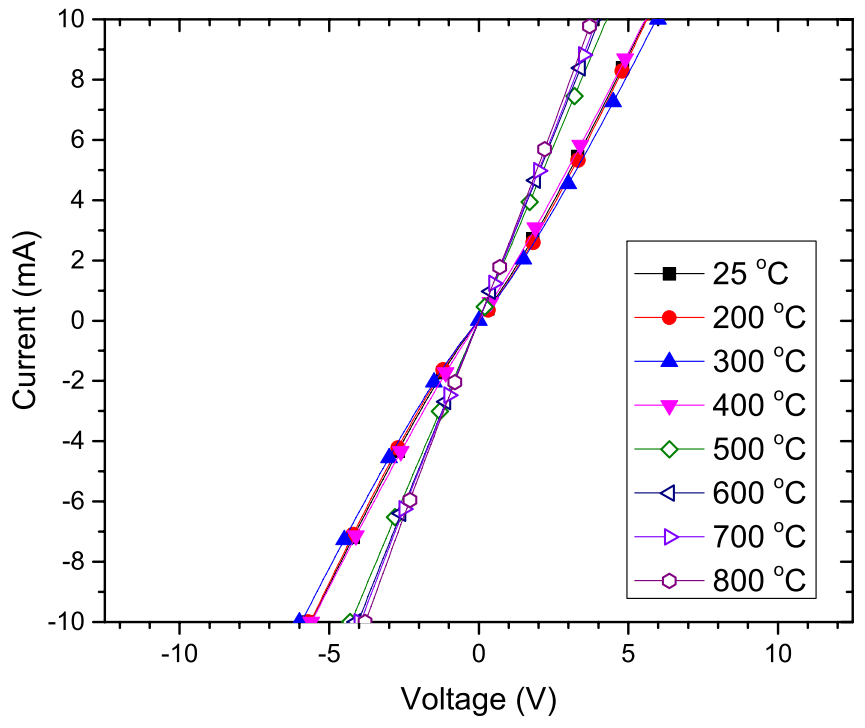

FIG. 4. (Color online) Progression of the current-voltage curve for different annealing temperatures for $\mathrm{Ni} / \mathrm{Au}$ contacts with a spacing of $10 \mu \mathrm{m}$. After annealing at $500{ }^{\circ} \mathrm{C}$ for $30 \mathrm{~s}$, the curves become steeper (open markers), a result of reducing the contact resistance.

as a function of anneal temperature, with specific contact resistance values of $\sim 2-4 \times 10^{-3} \Omega \mathrm{cm}^{2}$ and $\sim 2-4 \times 10^{-4} \Omega$ $\mathrm{cm}^{2}$ in the low and high temperature regimes, respectively. The specific contact resistance is only slightly lowered by annealing above $500^{\circ} \mathrm{C}$. Such a step-like change in the annealing temperature range of $400-500{ }^{\circ} \mathrm{C}$ is most likely due to a metal-semiconductor interfacial reaction.

After annealing at $800{ }^{\circ} \mathrm{C}$ for $30 \mathrm{~s}$, the metal contacts display visible signs of reaction with $\mathrm{B}_{12} \mathrm{P}_{2}$ around the edges of contact pads. Figure 6 shows the edge of a Ni/Au contact prior to annealing and the edge of two contacts originally spaced $5 \mu \mathrm{m}$ apart after annealing at $800^{\circ} \mathrm{C}$ for $30 \mathrm{~s}$. The edge of the contacts clearly diffuses outward, and droplets form around the periphery, suggesting that the edge reaches

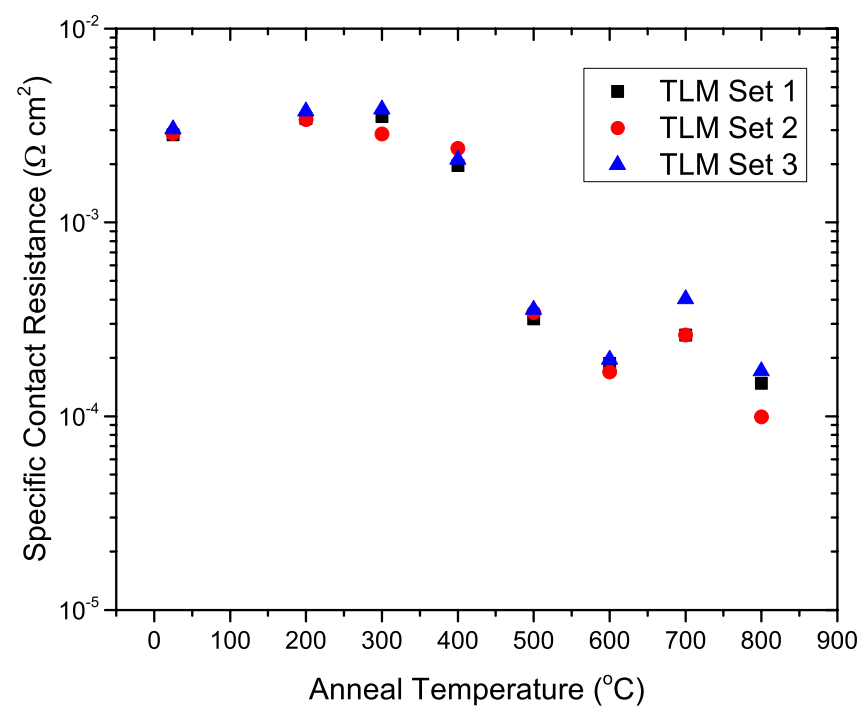

FIG. 5. (Color online) Change in the specific contact resistance of $\mathrm{Ni} / \mathrm{Au}$ contacts as a function of anneal temperature. Three sets of TLM patterns were tested after each anneal.

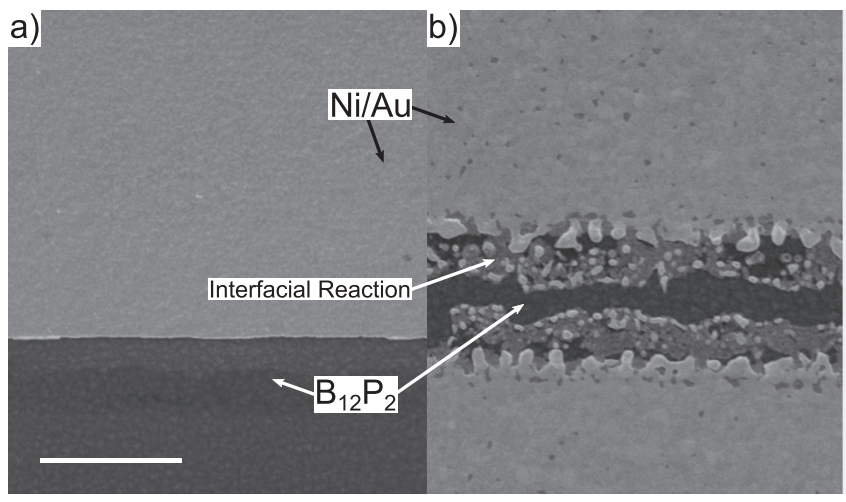

FIG. 6. SEM micrograph of (a) Ni/Au contact edges before annealing and (b) space between two Ni/Au contacts originally $5 \mu \mathrm{m}$ wide after annealing at $800^{\circ} \mathrm{C}$ for $30 \mathrm{~s}$. The edges of the contacts become rough and spread outward after annealing. The scale bar is $6 \mu \mathrm{m}$.

a eutectic during the annealing. From the Ni-Au phase diagram, ${ }^{31}$ the droplets at the edge cannot be a result of a eutectic caused solely by the metals since the $\mathrm{Ni}-\mathrm{Au}$ eutectic is above $950{ }^{\circ} \mathrm{C}$. Therefore, the metal must be reacting with the underlying $\mathrm{B}_{12} \mathrm{P}_{2}$. Since none of the binary phase diagrams of the elements of interest have eutectics below $850{ }^{\circ} \mathrm{C},{ }^{32,33}$ the droplets must be a three or more component mixture. The center of the contact remains intact but has speckles over the surface [Fig. 6(b)]. This may be caused by Ni diffusion and segregation at the sample surface, which is common for $\mathrm{Ni} / \mathrm{Au}$ contacts on other materials such as $\mathrm{GaN} .^{34-37}$

To further investigate the interfaces in the $\mathrm{Au} / \mathrm{Ni} / \mathrm{B}_{12} \mathrm{P}_{2}$ system, RBS was performed on a sample before any heat treatment and after the $500{ }^{\circ} \mathrm{C}$ anneal, which caused a major change in the $I-V$ characteristics. The RBS spectra are shown in Fig. 7. Before annealing, the spectrum reflects nonintermixed layers of $\mathrm{Au}$ and $\mathrm{Ni}$ on $\mathrm{B}_{12} \mathrm{P}_{2}$. Again, the $\mathrm{Ni}, \mathrm{P}$, and $\mathrm{B}$ peak edges (roughly located at $1.45,1.0$, and $0.32 \mathrm{MeV}$, respectively) are shifted to lower energies since those elements are located beneath the sample surface. During

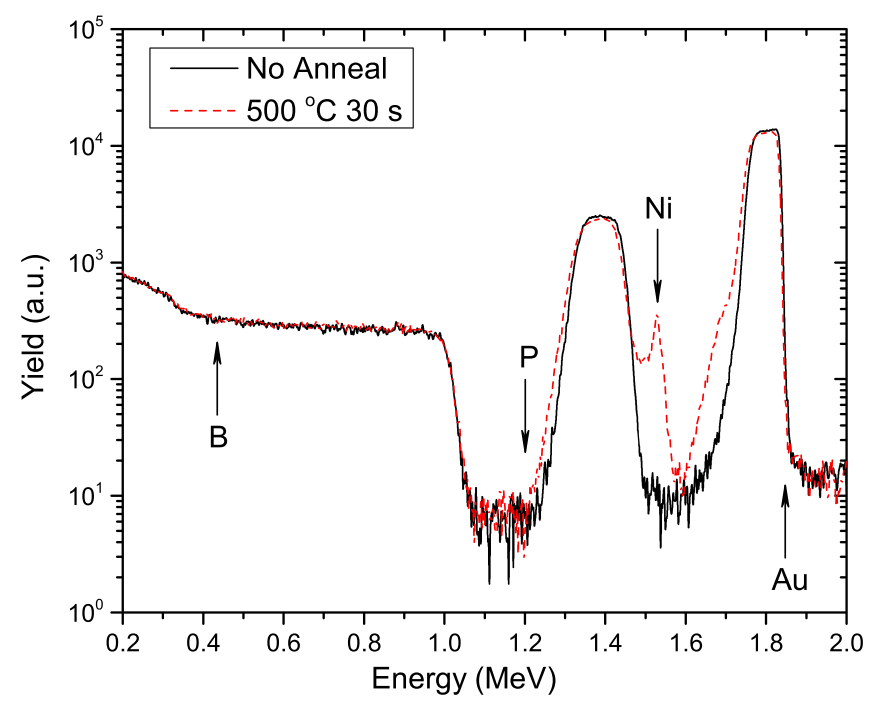

FIG. 7. (Color online) Semilog plot of RBS spectra for Ni/Au contacts before any heat treatment and after annealing at $500{ }^{\circ} \mathrm{C}$ for $30 \mathrm{~s}$. The positions of the surface peaks of $\mathrm{Au}, \mathrm{Ni}, \mathrm{P}$, and $\mathrm{B}$ are denoted by arrows. 
annealing, Au and Ni layers interdiffuse, as indicated by the broadening of the Au peak to lower energies and the Ni peak to higher energies. In addition, after the anneal, a small, sharp Ni peak is present at the energy corresponding to the sample surface, confirming Ni diffusion to the surface of the contact. A slight broadening of the Ni peak to lower energies after the $500^{\circ} \mathrm{C}$ anneal suggests lateral nonuniformity in the Ni layer thickness. This is consistent with SEM observations [Fig. 6(b)]. The fact that RBS signals from $\mathrm{B}$ and $\mathrm{P}$ are unchanged upon annealing at $500^{\circ} \mathrm{C}$ indicates that the reaction layer thickness and diffusion length of these elements must be less than $\sim 25 \mathrm{~nm}$-the detection limit of this RBS measurement. In spectra taken after anneals up to $800^{\circ} \mathrm{C}$ (not shown), the $\mathrm{P}$ peak is shifted to higher energies and confirms an increase of the reaction layer thickness.

The above results show that annealing at $500{ }^{\circ} \mathrm{C}$ for $30 \mathrm{~s}$ is sufficient to lower the $\mathrm{Ni} / \mathrm{Au}$ contact resistance without spreading of the metal contacts along the $\mathrm{B}_{12} \mathrm{P}_{2}$ surface. This anneal temperature is also low enough to avoid the annealing-induced reduction in sheet resistivity reported by Wang et al. ${ }^{10}$ while still attaining reasonably low contact resistances. Hence, annealing at $500^{\circ} \mathrm{C}$ for $30 \mathrm{~s}$ is the optimum procedure in this study.

\section{Comparison of $\mathrm{Ni} / \mathrm{Au}$ and $\mathrm{Cr} / \mathrm{Pt}$ contacts}

$\mathrm{Ni} / \mathrm{Au}$ and $\mathrm{Cr} / \mathrm{Pt}$ contacts differ in several key ways. First, unlike $\mathrm{Cr} / \mathrm{Pt}$, the as-deposited $\mathrm{Ni} / \mathrm{Au}$ contacts are ohmic. The measured sheet resistance between the $\mathrm{Cr} / \mathrm{Pt}$ sample and $\mathrm{Ni} /$ $\mathrm{Au}$ sample are not significantly different, and variations in the $\mathrm{B}_{12} \mathrm{P}_{2}$ conductivity cannot be attributed for the difference in conduction. In fact, the sheet resistance for the $\mathrm{Ni} / \mathrm{Au}$ film is slightly greater $\left(3.2 \times 10^{3} \Omega / \square\right.$ versus $1.8 \times 10^{3} \Omega / \square$ for $\mathrm{Cr} / \mathrm{Pt}$ ). One possible explanation for the difference in the conduction mechanism for the as-deposited condition is that $\mathrm{Ni}$ has a higher work function than $\mathrm{Cr}$ (as shown in Table I) and lowers the barrier height. A second explanation is that $\mathrm{Cr}$ is more susceptible to oxidation (for instance, from residual water vapor in the metal evaporation system) and could form an oxide barrier between $\mathrm{B}_{12} \mathrm{P}_{2}$ and $\mathrm{Cr}$. Another difference between the $\mathrm{Ni} / \mathrm{Au}$ and $\mathrm{Cr} / \mathrm{Pt}$ contacts is the alloying characteristics necessary for low resistance contacts. The $\mathrm{Cr} /$ Pt contacts not only need to react with the surface of $\mathrm{B}_{12} \mathrm{P}_{2}$ to become ohmic, but the contacts must react to a much greater degree than $\mathrm{Ni} / \mathrm{Au}$ to achieve a specific contact resistance on the order of $10^{-4} \Omega \mathrm{cm}^{2}$. Further, $\mathrm{Cr} / \mathrm{Pt}$ contacts redistribute both $\mathrm{B}$ and $\mathrm{P}$ throughout the depth of the contact. At $500{ }^{\circ} \mathrm{C}, \mathrm{B}$ and $\mathrm{P}$ are essentially immobile in the $\mathrm{Ni} / \mathrm{Au}$ system.

\section{CONCLUSION}

$\mathrm{Cr} / \mathrm{Pt}$ and $\mathrm{Ni} / \mathrm{Au}$ ohmic contacts to $p$-type $\mathrm{B}_{12} \mathrm{P}_{2}$ were developed. $\mathrm{Cr} / \mathrm{Pt}$ contacts became ohmic after annealing at $700^{\circ} \mathrm{C}$ for $30 \mathrm{~s}$ with a specific contact resistance of $2 \times 10^{-4}$ $\Omega \mathrm{cm}^{2}$. RBS demonstrates that $\mathrm{Cr}, \mathrm{Pt}, \mathrm{B}$, and $\mathrm{P}$ intermix before ohmic conduction is achieved. Ni/Au contacts, however, are ohmic in the as-deposited condition and have a specific contact resistance of $3 \times 10^{-4} \Omega \mathrm{cm}^{2}$ after annealing at
$500{ }^{\circ} \mathrm{C}$ for $30 \mathrm{~s}$. RBS indicates that the reaction layer between $\mathrm{Ni}$ and $\mathrm{B}_{12} \mathrm{P}_{2}$ is less than $\sim 25 \mathrm{~nm}$ thick and that $\mathrm{Ni}$ diffuses to the sample surface. $\mathrm{Ni} / \mathrm{Au}$ contacts display superior properties than $\mathrm{Cr} / \mathrm{Pt}$ contacts, including ohmic conduction prior to annealing, better thermal stability, and a similar contact resistance at a lower anneal temperature that is also below the observed temperature that causes a reduction in sheet resistance in icosahedral borides.

In future work, increasing the dopant level in $\mathrm{B}_{12} \mathrm{P}_{2}$ may aid in reducing the specific contact resistance. $\mathrm{Si}$, a $p$-type dopant in $\mathrm{B}_{12} \mathrm{As}_{2}$, could be coevaporated with $\mathrm{Ni}$. Alternatively a thin Si film could be evaporated prior to $\mathrm{Ni}$ evaporation. While sintering the contact, Si may diffuse into the $\mathrm{B}_{12} \mathrm{P}_{2}$ directly beneath the contact, locally increase the doping concentration, and lower the contact resistance. Such a scheme may become even more important when creating ohmic contacts to $\mathrm{B}_{12} \mathrm{P}_{2}$ that has a lower background doping level.

\section{ACKNOWLEDGMENTS}

This work was performed under the auspices of the U.S. Department of Energy by Lawrence Livermore National Laboratory under Contract Nos. DE-AC52-07NA27344 and LLNL-JRNL-666166. Material growth was supported by the U.S. Department of Energy, Office of Basic Energy Sciences under Award No. DE-SC0005156.

${ }^{1}$ G. A. Slack, T. F. McNelly, and E. A. Taft, J. Phys. Chem. Solids 44, 1009 (1983).

${ }^{2}$ D. Emin, J. Solid State Chem. 179, 2791 (2006).

${ }^{3}$ M. Carrard, D. Emin, and L. Zuppiroli, Phys. Rev. B 51, 11270 (1995).

${ }^{4}$ Y. Zhang et al., MRS Proceedings (Cambridge University, Cambridge, United Kingdom, 2011), Vol. 1307, p. mrsf10-1307.

${ }^{5}$ Y. Zhang et al., J. Cryst. Growth 352, 3 (2012).

${ }^{6}$ Z. Xu, J. H. Edgar, D. C. Look, S. Baumann, R. Bleiler, S. H. Wang, and S. E. Mohney, J. Appl. Phys. 101, 053710 (2007).

${ }^{7}$ Y. Gong, M. Tapajna, S. Bakalova, Y. Zhang, J. H. Edgar, M. Dudley, M. Hopkins, and M. Kuball, Appl. Phys. Lett. 96, 223506 (2010).

${ }^{8}$ J. O. Song, J.-S. Ha, and T.-Y. Seong, IEEE Trans. Electron Devices 57, 42 (2010).

${ }^{9}$ Y. Ino, S. Nishimura, M. Hirai, S. Matsumoto, and K. Terashima, Jpn. J. Appl. Phys. 52, 031201 (2013).

${ }^{10}$ S. H. Wang, E. M. Lysczek, B. Liu, S. E. Mohney, Z. Xu, R. Nagarajan, and J. H. Edgar, Appl. Phys. Lett. 87, 042103 (2005).

${ }^{11}$ Y. Kumashiro, T. Yokoyama, T. Sakamoto, and T. Fujita, J. Solid State Chem. 133, 269 (1997).

${ }^{12}$ Y. Kumashiro, H. Yoshizawa, and K. Shirai, JJAP Ser. 10, 166 (1994).

${ }^{13}$ M. Takigawa, M. Hirayama, and K. Shohno, Jpn. J. Appl. Phys. 12, 1504 (1973).

${ }^{14}$ S. N. L'vov, V. F. Nemchenko, P. S. Kislyi, T. S. Verkhoglyadova, and T. Y. Kosolapova, Sov. Powder Metall. Met. Ceram. 1, 243 (1962).

${ }^{15}$ Dictionary of Inorganic Compounds, 1 st ed., edited by J. E. Macintyre (Chapman and Hall/CRC, London, UK, 1992), Vol. 5, p. 3082.

${ }^{16}$ H. Okamoto, J. Phase Equilib. 24, 480 (2003).

${ }^{17}$ M. Venkatraman and J. P. Neumann, Bull. Alloy Phase Diag. 11, 430 (1990).

${ }^{18} \mathrm{~B}$. Predel, in $B-B a C-Z r$, Landolt-Brnstein-Group IV Physical Chemistry, edited by O. Madelung (Springer, Berlin, Heidelberg, 1992), Vol. 5b, pp. $1-3$.

${ }^{19}$ H. Okamoto, Bull. Alloy Phase Diag. 11, 511 (1990).

${ }^{20}$ M. D. Smolin, V. G. Grebenkina, Y. M. Goryachev, L. I. Panov, and E. I. Shvartsman, Sov. Powder Metall. Met. Ceram. 21, 662 (1982).

${ }^{21}$ I. Shirotani, E. Takahashi, N. Mukai, K. Nozawa, M. Kinoshita, T. Yagi, K. Suzuki, T. Enoki, and S. Hino, Jpn. J. Appl. Phys. 32, 294 (1993).

${ }^{22}$ N. Kobayashi, Y. Kumashiro, P. Revesz, J. Li, and J. W. Mayer, Appl. Phys. Lett. 54, 1914 (1989). 
${ }^{23}$ R. I. Stearns and P. E. Greene, J. Electrochem. Soc. 112, 1239 (1965).

${ }^{24}$ U. Nwagwu, "Flux growth and characteristics of cubic boron phosphide," Master's thesis (Kansas State University, 2012).

${ }^{25}$ T. L. Chu, M. Gill, and R. K. Smeltzer, J. Cryst. Growth 33, 53 (1976).

${ }^{26}$ D. K. Schroder, Semiconductor Material and Device Characterization, 2nd ed. (Wiley-Interscience, New York, 1993), Chap. 3, pp. 133-199.

${ }^{27}$ F. A. Padovani and R. Stratton, Solid-State Electron. 9, 695 (1966).

${ }^{28}$ D. Eastman, Phys. Rev. B 2, 1 (1970).

${ }^{29}$ M. Venkatraman and J. P. Neumann, Bill. Alloy Phase Diag. 11, 16 (1990).

${ }^{30}$ P. B. Klein, U. Nwagwu, J. H. Edgar, and J. A. Freitas, Jr., J. Appl. Phys. 112, 013508 (2012).
${ }^{31}$ T. A. Hall and A. A. Johnson, J. Less Common Met. 141, L19 (1988).

${ }^{32}$ H. Okamoto, J. Phase Equilib. 21, 210 (2000).

${ }^{33}$ O. Teppa and P. Taskinen, Mater. Sci. Technol. 9, 205 (1993).

${ }^{34}$ H. W. Jang, S. Y. Kim, and J.-L. Lee, J. Appl. Phys. 94, 1748 (2003).

${ }^{35}$ A. Motayed, A. V. Davydov, L. A. Bendersky, M. C. Wood, M. A. Derenge, D. F. Wang, K. A. Jones, and S. N. Mohammad, J. Appl. Phys. 92, 5218 (2002).

${ }^{36}$ Y. Koide, T. Maeda, T. Kawakami, S. Fujita, T. Uemura, N. Shibata, and M. Murakami, J. Electron. Mater. 28, 341 (1999).

${ }^{37}$ J.-K. Ho, C.-S. Jong, C. C. Chiu, C.-N. Huang, K.-K. Shih, L.-C. Chen, F.R. Chen, and J.-J. Kai, J. Appl. Phys. 86, 4491 (1999). 